\title{
Teaching Fellows Program: Undergraduate Partners in Teaching
}

\author{
Dr. Janet A. Schmidt, Ms. Jane F. Fines, and Dr. Gary A. Pertmer \\ University of Maryland College Park
}

\section{Introduction:}

One of the most significant and enduring legacies of the NSF-sponsored ECSEL coalition at the University of Maryland at College Park is the Teaching Fellows program. Begun in 1992, the program was originally conceived as an opportunity for advanced undergraduates to assist faculty in the delivery of the Introduction to Engineering Design (ENES 100) class. Because ENES 100 was designed to be a "hands on" experience where first year students were introduced to the design process through the realization of an actual product (e.g., human powered water pump) by working in small teams, Teaching Fellows (called TFs) have a variety of roles atypical of most undergraduate teaching assistants. ${ }^{2}$ Specifically, TFs act as role models, tutors, and team facilitators in addition to assisting the faculty member with tasks such as grading, supervising study sessions and occasionally teaching a class section on material related to the class project or team dynamics. The purpose of the present paper is to describe the Teaching Fellows program today, ten years after its inception. While many features have remained virtually the same, significant changes in the students targeted for inclusion in the TF program, their training, as well as the curriculum completed by the first year students merit an update at this time.

\section{Recruitment:}

Technology has made the recruitment of TFs easier than it was ten years ago. Students are informed of the opportunity to become a TF by the college's electronic list serv (FYI: For Your Information). Minimum requirements include satisfactory GPA, prior successful experience with the course, and interest in completing the required one credit seminar (ENES 388T Seminar in College Teaching). Applications are also provided online and ask students to provide a description of their college activities including involvement in student organizations and projects, relevant leadership, tutoring, or teaching experiences, as well as a statement of interest in the TF position. Transcripts and references are also required. Based on these materials, a group of qualified applicants is invited to be interviewed.

Interviews with interested students are conducted by the Associate Dean of Engineering. The students' academic records are reviewed, their prior experience with the course, including identification of the strengths and weaknesses associated with the particular project being done in ENES 100 that year, and background in teaching or tutoring. Expectations for the position are explained including the time commitment (ten hours per week), attendance in some percentage of the ENES 100 class sessions, office hours and tutoring duties, as well as the required training and seminar. Unlike in years past, juniors and seniors are encouraged to apply to the TF 
program. We have observed that junior status students have enough engineering background and maturity to be successful TFs. And because students are paid a stipend for their role as Teaching Fellows, the position is seen as desirable. More than just seniors thinking about a career in engineering education, many students see this program as an enjoyable way to help assist with college expenses. From the standpoint of the program administrators, having students return to the program as experienced TFs significantly improves the quality of the undergraduate ENES 100 experience. Therefore, in addition to the criteria noted above, and efforts to select a diverse group of TFs in terms of gender and ethnicity, some preference is given to outstanding junior level applicants as well as returning TFs.

\section{Training: Involving the BESTEAMS Partnership}

While TFs are assigned to specific sections of ENES 100 and work closely with individual faculty members, the seminar and training is conducted by college student personnel professionals in the Engineering Dean's office. The one credit course taken by the TFs entitled "Seminar in College Teaching" instituted in 1994 has gone through various iterations. Originally set up with weekly two hour meetings throughout the semester, the course's dual purpose was to provide group processing time where TFs could discuss course issues and problems and well as addressing issues related to the successful teaching of college freshmen. For example, topics such as learning styles, classroom climate issues (gender and race/ethnicity), and student developmental theories are among the original topics still included in the current seminar.

With the advent of ABET's new EC 2000 directives for the satisfactory education of undergraduate engineers, greater emphasis has been placed on the role of teamwork in the engineering classroom. ${ }^{14}$ In the early 1990 's, ENES 100 was likely to be the only team based course that many engineering students could expect as undergraduates. Today, a number of engineering majors require team projects in many courses. Given the increase in the number of team projects required, it is interesting to note most engineering faculty still have little or no training in the facilitation of successful student teams. Within this context, a group of faculty and administrators at the Clark School of Engineering began developing team training materials for faculty and students in the college. After several years of pilot work, ${ }^{10}$ the group secured NSF funding in 2001 to develop BESTEAMS (Building Effective Student Teams in Engineering and Management Systems).

The BESTEAMS project is developing a flexible series of team training modules that can be administered in a variety of formats throughout the standard engineering curriculum. There are three main "tracks" related to important aspects of successful team functioning: Personal Awareness, Interpersonal Effectiveness, and Project Management. Each track consists of three levels (Introductory, Intermediate, and Advanced). In ENES 100, the introductory level modules are taught. Therefore a significant, new component of TF training is the inclusion of BESTEAMS team training materials. What follows is a detailed description of the Teaching Fellows seminar, including the BESTEAM materials.

\section{The Seminar in College Teaching:}

The seminar in college teaching consists of a series of modules that are designed to provide the Teaching Fellows with the knowledge, skills, and processes for working effectively with their students and their faculty instructional partner. Additionally, some basics for teaching a class such as developing a syllabus and lessons plans are also discussed as well as ethics in teaching. 
The modules typically include a lecture or discussion with activities related to ENES 100 that are designed to apply knowledge or practice skills. Activities include case studies, simulations, demonstrations, and role-playing. Several of the modules are discussed below.

Understanding Your Students: One of the goals of the seminar is to help the Teaching Fellows develop a theoretical framework for understanding and interacting with their students. Nevit Sanford's person-environment model of challenge and support, Arthur Chickering's vectors of development, and Perry's scheme of intellectual and ethical development provide the TFs with a mechanism for understanding the cognitive and psychosocial development of their students and determine courses of action that will help their students in their development. After providing the TFs with an overview of the theories and how they apply in the classroom, cases are used to structure a discussion applying the theories to actual ENES 100 situations. The TFs also take Kolb's Learning Style Inventory (LSI), ${ }^{4,8}$ which forms the basis for a discussion of the characteristics of their students' learning styles, characteristics of teaching styles and the teacher's role, and learning activities associated with the various learning styles ${ }^{7}$. The module on Kolb's LSI also provides the background material for the BESTEAMS introductory level interpersonal awareness and interpersonal effectiveness modules that will be discussed later.

Group Dynamics and Teamwork: The TFs begin this module with a self-assessment of their own group leadership skills followed by a general discussion of the importance for engineers to work effectively in teams and the Teaching Fellow as team facilitator, including the role of the facilitator and skills for facilitators to use and to teach (i.e., communications skills ${ }^{5,11,12}$ ). The stages of team development - form, storm, norm, perform, adjourn - are used as the framework for the module on teamwork and group dynamics. The TFs are guided through a discussion of the characteristics of the various stages of team development, and they practice the skills and processes necessary to manage the stages. TFs perform get-acquainted and teambuilding activities that can be used during the forming stage, discuss team member roles and behaviors and how to handle difficult team members during the storming stage, practice brain-storming, problem-solving, and decision-making skills needed during the norming and performing stages, and learn to use the team and peer evaluation forms utilized during the adjourning stage. The third BESTEAMS introductory module on project management, ${ }^{13}$ which is discussed later in this paper, is also demonstrated.

Assessing Student Performance: Teaching Fellows, over the years, have been involved with assessing their students' performance in ENES 100. In this module, Bloom's "Taxonomy of Educational Objectives" $" 18$ and how it relates to Kolb's learning cycle ${ }^{7,8}$ are reviewed. Suggestions for preparing quizzes, tests and exams and grading practices for tests ${ }^{19}$ and written and oral reports are also discussed. ${ }^{20}$ TFs practice developing test questions that can be used on an ENES 100 quiz or exam.

Academic Integrity: Since Teaching Fellows will likely function as proctors for quizzes and exams and also be involved in grading tests and papers as well as serve as role models for their students, they have a major role in promoting and preserving academic integrity. TFs must be familiar with the academic integrity policies and procedures for the University of Maryland and know and apply strategies for preventing academic dishonesty ${ }^{19}$.

Classroom Climate: ENES 100 is the introductory course for new engineering students, and it is important for retention purposes that all students find an environment that is supportive and that encourages equitable participation. ${ }^{3,6,9,15}$ Tips for good teaching practices in a diverse 
classroom ${ }^{19}$ are discussed and the University of Maryland's "Statement on Classroom Climate" and the "Statement on Sexual relationships and Professional Conduct" are reviewed with the Teaching Fellows. The TFs also participate in Sexual Harassment Prevention training.

The Teaching Fellows are provided with a Seminar in College Teaching Resource Manual that includes the information, processes, forms, and examples described above as well as supplemental articles to read on their own.

\section{BESTEAMS Introductory Modules:}

As noted above, BESTEAMS has developed three levels of training modules related to teams. The introductory level consisting of 3 modules is taught in ENES 100. The TFs are a critical part of the delivery of these modules. In all cases they assist the faculty member in the delivery of the modules. In some cases, they themselves deliver a team module as a requirement of their seminar on college teaching. TFs and the faculty are trained in module delivery during a seminar prior to the beginning of each semester. The modules are briefly described below:

Interpersonal Awareness: One of the key assumptions in the BESTEAMS model of team work is that individual awareness of one's own strengths and weaknesses is important to successful team functioning. Beyond clarifying what each student can best bring to the team project, this module also introduces the idea that individual differences exist and that diversity on a team enhances team functioning. Individual differences or attributes can be interpreted in a number of ways. Common attribute filters include the Myers-Briggs Personality types, gender, and GPA. Some classification systems have more merit than others. BESTEAMS has chosen to use the attribute of learning styles as the attribute filter for team training for the following reasons:

- Identification of an individual's style helps them in understanding themselves as learner.

- The model is straightforward and allows easy self-assessment (Kolb Learning Style Inventory. ${ }^{8}$

- Understanding style differences influences member-to-member and team-to-member interactions.

- Understanding of style differences influences faculty-student and faculty-class interactions.

- Learning styles reflect a relevant aspect of diversity present in many engineering teams.

The Introductory Personal module provides faculty and TFs with guidelines in how to use the LSI in an engineering team context. Moreover, the training materials provide suggestions for how to continue to integrate the notion of learning styles and individual differences throughout the semester through classroom exercises, homework and examination questions.

Interpersonal Effectiveness: This module addresses several key aspects of interpersonal functioning within student project teams. Specifically, students will learn skills fundamental to successful teams: knowledge of typical stages of team development; giving and receiving feedback (with emphasis on developing good listening skills); and tools for generating new ideas in teams (e.g., brainstorming strategies). For students who have already been trained in the Kolb Learning Style, an optional training section outlines uses of their knowledge of Kolb learning styles in the context of team dynamics. Faculty are provided with an outline of the material including a generic power point presentation that can be adapted according to their preferences, 
additional background reading on related subjects, as well as handouts for the students that can be used during the semester to evaluate team interpersonal dynamics.

Project Management: This module addresses several key aspects of project management within student project teams. Specifically, students will learn skills fundamental to being able to create and operate a project management schedule. For many freshmen and sophomores, we need to address maintaining a personal time management system as a required precursor to appreciating what is needed for a project timeline. This module is designed to teach students an appreciation of personal time management that focuses on managing "accomplishments" or tasks in time. Exercises are done that help them organize their own schedules building backwards from key deliverables/due dates for course projects. In the extended version of this module, students are introduced to organizing an actual project using a Work Breakdown Structure, and, as homework, complete Gantt charts of the ENES 100 class project.

\section{Plans for the future: The extended TF program}

After over ten years of operating various versions of ENES 100 and the Teaching Fellows program, we feel prepared to expand our program by increasing the number of students who become TFs by including courses other than ENES 100, encouraging TF retention in the program by creating a new track of "Senior Teaching Fellows," and ultimately developing a citation program in Engineering Professional Skills, of which participation in the TF program will be a part.

The establishment of a new track or set of positions ("Senior Teaching Fellow Program") is designed to recognize the increasing experience of TFs as they assist faculty over multiple semesters. As noted earlier, many students accept this job because it is a chance to build their resumes by learning new skills and building closer relationships with faculty members. Over time, these ambitious students need new incentives, new skills to learn if they are to maintain interest in the position. As a first step in launching such an effort, a pilot was run in Fall 2001with four designated Senior Teaching Fellows. All were experienced TFs in ENES 100. Among their new tasks was taking a lead role in teaching the one credit seminar on college teaching to the new incoming TFs. In addition, they were a "test group" to evaluate ideas related to the current semester, choice of future design projects, and about the future of the new Senior TF track.

During the semester, the Senior Teaching Fellows met weekly to share impressions of the course and their role. Senior TFs reported often feeling frustrated when working with professors new to ENES 100. By virtue of their training, most had more background about student characteristics and how to handle the students in a project team setting than did their instructors. The gap between the beginning professors and themselves was such that many TFs discussed the pros and cons of "moving on" to other college jobs. At the end of the pilot, TFs were assessed in terms of why they had repeatedly returned to the Teaching Fellows program and what they obtained from the experience. Most reported wanting to continue with the program despite their frustration with some faculty because they appreciated working with freshmen and enjoyed the privileges associated with the position. Based on their input and their experiences, the following new job description for Senior TFs was developed: 


\section{Job Description for ENES 100 Senior Teaching Fellows}

1. Assist in training of new Teaching Fellows via participation in the college teaching seminar

2. Coordinate with BESTEAMS for activities related to team training and assessment in ENES 100

3. Assist with regularly scheduled TF meetings to monitor on going class and instructor dynamics

4. Mentor new TFs in group dynamics, conflict management, and instructor-TF interactions

5. Participate in one additional activity to support the development of ENES 100. Examples include: updating the ENES 100 website; working with LEGOS to develop engineering applications; work with BESTEAMS on development of advanced team training materials; work with the IT component of the course to develop visualizations and simulations exercises to be used in ENES 100

6. Participate in an annual focus group reflecting on the strengths and weaknesses of ENES 100.The Senior TF input will be used in decisions related to the selection of future student design projects, faculty training, as well as the development of a citation program in Professional Engineering Skills, see below.

In addition to clearly outlining the responsibilities of the new Senior TFs as just described, there will be an increase in their financial compensation and the option for them to earn additional academic credits if they desire.

Based on this pilot work, we have confidence that developing a more complex and meaningful track for Senior TFs should result in greater satisfaction and persistence among the TF population. By increasing continuity among TFs and being able to select only the best to become a part of the Senior Teaching Fellows, the overall TF program will become more prestigious. As the reputation of the program builds and more the students see the "value added" of participating in the TF program, we concurrently plan to develop a college-wide citation called "Engineering Professional Skills." To complete a citation program, a student must complete six courses in addition to those required by their engineering major. Based on the input from employers and new ABET accreditation standards, the citation in Engineering Professional Skills will include course work in communication (multicultural and international), project management, teamwork, and ethics related to engineering practice. Students who complete the Teaching Fellow and Senior Teaching Fellow experience will be eligible to waive the teamwork course requirement. Note, the citation program will be open to engineering students who choose not to participate in the TF program. The requirements of the citation program will be flexible so the maximum number of interested students can participate.

\section{Conclusion:}

It is interesting to compare the status of the current Teaching Fellows Program with a paper written in 1995: "Building Community Through A Freshman Introduction to Engineering Design Course: The ECSEL Teaching Fellows Program," written by J.Fines, T. Regan and K. Johnson, and presented at the 1995 ASEE conference. That piece concludes with several recommendations for the continued success of the program. The aspects that have been addressed over the years include an increased focus on "group process skills and conflict 
management" in the form of the BESTEAMS team training program and greater focus on diversity issues (also explicitly addressed in the BESTEAMS training).

Aspects that were noted at that time and continue to need attention include more thorough training of the TFs in the technical aspects of the specific ENES 100 student project and further strengthening of the relationship between the teaching fellow and the faculty instructor. While now both faculty and TF participate in BESTEAMS training and discuss the role and expectations of the TF, more could be done to build a solid foundation for an effective working relationship. Perhaps faculty and TFs should attend joint meetings throughout the semester to discuss the progress of the course. Or, a mid-semester feedback session might be built into the program which requires faculty and TF to sit down to together to assess the status of the class and their interaction.

Finally, while the success of the program has increased the number of TFs to be found in other classes, such as thermodynamics, many of these students do not actually participate in the TF seminar in college teaching (most have already completed it). We feel our plans to establish the senior teaching fellow track will act as an incentive so that students will be want to "remain connected" to our program and see TF positions beyond ENES 100 as more than just jobs. Instead, combined with didactic work, involvement as a TF in a series of classes could result in the completion a citation in Engineering Professional Skills. By having documented evidence of professional skills such as leadership, conflict management, and project management, Teaching Fellows will stand out in the competition for jobs compared to peers who rely on technical competence alone.

\section{Bibliography}

1 Cook, L., Kling, M., Moy, A., Praske, K., Selenow, T., and Kinney, A., Capturing the QUEST Mentor Experience: A Guide to Managing Student Teams, unpublished manuscript, (2000).

2 Dally, J. Introduction to Engineering Design: Book 6 (Projects and Success Skills), College House Enterprises, LLC, Knoxville, TN. (2001).

3 Desjardins, C., "The Meaning of Gilligans Concept of Different Voice for the Learning Environment,"Educating the Majority: Women Challenge Tradition in Higher Education, Eds. C.S. Pearson, D.L. Shavlik, and J.G. Touchton, MacMillan Publishing, New York, pp121-133 (1989) .

4. Felder, Richard M., Silverman, Linda K.,'Learning and Teaching Styles in Engineering Education, ” Engineering Education, (1998).

5 Gibbs, Graham, Learning in Teams: A Student Manual, rev. ed., Oxford Press, (1997).

6 Guys-Sheftall, B. and P. Bell-Scott, Black Women's Studies: “A View From the Margin,” Educating the Majority: Women Challenge Tradition in Higher Education, Eds. C.S. Pearson, D.L. Shavlik, and J.G. Touchton, MacMillan Publishing, New York, pp 205-218 (1989) .

7 Harb, J.N. \& R.E. Terry, “Writing Through the Cycle: Application of Learning Style Theory to Engineering Education at Brigham Young University", unpublished draft, (1995).

$8 \quad$ Kolb Learning Style Inventory and Worksheet, McBer \& Company, 1985. Boston, MA Brassard, M. \& D. Ritter, The Memory Jogger II, GOAL/QPC Publishers, Methuen, MA, (1994).

9 McIntosh, P.M., "Curricular Re-Vision: The New Knowledge for a New Age,"Educating the Majority: Women Challenge Tradition in Higher Education, Eds. C.S. Pearson, D.L. Shavlik, and J.G. Touchton, MacMillan Publishing, New York, pp. 400-412, (1989). 
Mead, P.F., Moore, D., Natishan, M., Schmidt, L., Goswami, I., Brown, S., Lathan, C., Mouring, S., "Faculty and Student Views on Engineering Student Team Effectiveness, "Journal of Women and Minorities in Science and Engineering, vol. 5, (1999).

11 Myers, S. Team Building For Diverse Work Groups, Richard Chang Publications, Irvine, CA. (1996).

12 Scholtes, P., The Team Handbook, Joiner Associates, Madison, WI., (1988).

13 Smith, K. Project Management and Teamwork, McGraw- Hill. Boston, (2000).

14 Peterson, George ABET Engineering Criteria 2000, Keynote address, 1998 WEPAN National Conference, Seattle, WA. (1998).

15 Rosser, S. V., Re-Engineering Female Friendly Science, Teachers College Press, Teachers College, Columbia University, New York, pp50-52, (1997).

16 Wilde, D., "Using Team Preferences to Guide Design Team Composition," Proceedings of DETC '97, 1997 ASME Design Engineering Technical Conference, Sept. 14-17, DETC97/DTM-3890 (1997).

17 Hiebert, M., \& Colleagues (1998-2002) “Group Leadership Skills-An Assessment” Retrieved January 13, 2003, from the World Wide Web: http://www.consultskills.com/

18 Bloom B. S. and D. R. Krathwohl. Taxonomy of Educational Objectives: The Classification of Educational Goals, by a committee of college and university examiners. Handbook I: Cognitive Domain. New York, Longmans, Green, 1956.

19 Davis, B.G. Tools for Teaching Jossey-Bass Publishers: San Francisco (1993)

20 "Grading: Useful Techniques" TA Handbook 1998/1999 University of Guelph. Retrieved January 13, 2003, from the World Wide Web: http://www.tss.uoguelph.ca/tahb/tahindex.html

21 "Statement on Classroom Climate" Faculty Policies and Resources, University of Maryland, January 13, 2003, from the World Wide Web: http://www.inform.umd.edu/EdRes/FacRes/teach/classclimate.html

22 "Statement on Sexual Relations and Professional Conduct" VI-1.20(A) University Of Maryland Policy And Procedures On Sexual Harassment. University of Maryland Office of Legal Affairs. Retrieved January 13, 2003, from the World Wide Web: http://www.inform.umd.edu/PRES/policies/vi120a.html

Dr .JANET A. SCHMIDT, Director, Student Research, A. James Clark School of Engineering, an educational psychologist, Dr. Schmidt is a member of the BESTEAMS group and a co-instructor of the Teaching Fellows' seminar on college teaching.

Ms. JANE F. FINES, Director, Special Programs, A. James Clark School of Engineering, developed the Teaching Fellows program including the process for recruitment and selection of the Teaching Fellows as well as the training program, and is currently co-instructor of the Teaching Fellows' seminar on college teaching.

Dr. GARY A. PERTMER, Associate Dean, Education, A. James Clark School of Engineering, coordinates ENES 100 at the college level and is actively involved in the Teaching Fellows program. 